\title{
Aplicação de SIG no uso do MUSAG visando a diminuição dos riscos na produção agrícola. Bacia do Alto Rio Sucuru, Paraíba - um estudo de caso ${ }^{1}$
}

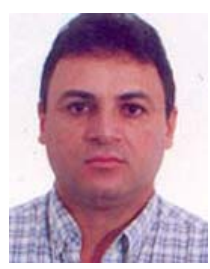

Guttemberg da S. Silvino² \& Marx P. Barbosa ${ }^{3}$

\author{
1 Parte da Dissertação de Mestrado do primeiro autor, apresentada na UFPB, Campina Grande, PB, Campus II \\ 2 SEMARH Centro Administrativo. Bloco II, $2^{\circ}$ Andar, Jaguaribe, CEP 58019-900, João Pessoa, PB. Fone: (83) 9307-3564. \\ E-mail: gugu@semarh.pb.gov.br (Foto) \\ 3 UFCG/CCT/DEAg. Fone: (83) 333-2355. E-mail: marx@Imrs-semarh.ufpb.br
}

Protocolo $4-16 / 1 / 2001$

\begin{abstract}
Resumo: O uso do Modelo de Umidade de Solos para Atividades Agrícolas (MUSAG) juntamente com um sistema de informações geográficas permitiu a criação de um banco de dados georreferenciado para gerar mapas temáticos, no auxílio à identificação da melhor data de plantio, em sequeiro, do milho e feijão, na região semi-árida paraibana. O resultado alcançado identificou o SIG como uma ferramenta importante para armazenar, recuperar e analisar mapas em ambiente computacional, com a inclusão de diferentes tipos de dados geográficos superpostos em forma digital, o que possibilitou a análise e mapeamento da umidade do solo visando auxiliar os tomadores de decisão no planejamento de programas de desenvolvimento socioeconômico para regiões semi-áridas, com base no desenvolvimento sustentável.
\end{abstract}

Palavras-chave: sistema de informações geográficas, umidade dos solos, MUSAG

\section{Application of GIS in the use of MUSAG seeking to reduce risks in the agricultural production. Basin of the Alto Rio Sucuru, Paraíba - A case study}

\begin{abstract}
The use of a soil moisture model for agricultural purposes "MUSAG" and a geographical information system permitted creation of a georeferenced database to generate thematic maps to assist the identification of the best date for plantation of rainfed corn and bean in the semi-arid area of the State of Paraíba. The attained results identify the GIS as an important tool to store, to recover and to analyze maps, with the inclusion of different types of overlapped geographical data in digital form, facilitating the mapping and analysis of soil moisture as a support for the decision making to plan socio-economic programs for the sustainable development of the semiarid region.
\end{abstract}

Key words: geographic information systems, soil moisture, MUSAG

\section{INTRODUÇÃO}

$\mathrm{Na}$ região do semi-árido nordestino os déficits hídricos ocorrem com bastante freqüência, colocando em risco a produção das culturas agrícolas anuais, que praticamente se desenvolvem em regime de sequeiro. A adequação da época de plantio com o nível favorável de umidade do solo é fundamental a uma segura germinação das sementes. A evolução dos sistemas computacionais tem proporcionado excelentes resultados no processo de automação da maioria dos trabalhos executados de forma convencional e tem permitido o processamento de um grande volume de informações relevantes para tomadas de decisão no nível da gestão ambiental. Ante as considerações expostas, neste trabalho objetiva-se aplicar o uso do Modelo de Umidade de Solos para Atividades Agrícolas - MUSAG, proposto por Molinas \& Andrade (1992) em um ambiente SIG para a determinação da umidade do solo e do déficit hídrico, visando à diminuição dos riscos na produção agrícola na Bacia do Alto Rio Sucuru, Paraíba.

\section{MATERIAL E MÉTODOS}

A área de estudo, com aproximadamente $981,2 \mathrm{~km}^{2}$, localiza-se na microrregião dos Cariris Velhos Paraibano, entre os paralelos $07^{\circ} 28^{\prime} 00^{\prime \prime}$ e $07^{\circ} 50^{\prime} 00^{\prime \prime}$ de latitude Sul e os meridianos $37^{\circ} 13^{\prime} 00^{\prime \prime}$ e $36^{\circ} 49^{\prime} 00^{\prime \prime}$ de longitude Oeste e a divisa dos Estados da Paraíba e Pernambuco, no extremo oeste englobando, total 
ou parcialmente, os municípios de Amparo, Monteiro, Ouro Velho, Prata e Sumé.

No desenvolvimento desse estudo foram utilizados dados bibliográficos e o mapa de alta intensidade de solos, na escala 1:100.000 (Silva, 1994). A localização dos pontos de teste de infiltração nas unidades de mapeamento de solos foi feita com o uso do Sistema de Posicionamento Global (GPS). Os suportes lógicos de software utilizados foram: MicroStation do Mapping Office, módulo de entrada de dados, onde foi digitalizado o mapa de solos, e o sistema de informações geográficas - MapInfo Profissional 5.0.

A avaliação do uso do MUSAG, em ambiente SIG, baseou-se na metodologia descrita por Molinas \& Andrade (1992) que recomendam a utilização do modelo para a estimativa de datas de plantio, com base nos dados de umidade do solo e na função de exigências de água das culturas de milho e feijão. Esta função foi estimada segundo os critérios de cálculo do "coeficiente de cultura - Kc" (Doorenbos \& Kassam, 1994) para períodos de 90 e 60 dias, associados aos ciclos do milho e do feijão, variedades usualmente utilizadas na área de estudo.

$\mathrm{O}$ algoritmo de determinação da data de plantio consiste na avaliação do déficit hídrico mínimo decorrente da diferença existente entre a função de exigências de água por parte das culturas e a umidade do solo, para cada dia do período em estudo.

Neste trabalho, o MUSAG foi ajustado ao nível regional, abrangendo toda a área de estudo, com a seguinte forma:

a) associação da área de influência de cada pluviômetro, com determinado tipo de solo ou conjunto de solos, adotandose a metodologia de Thiessen (Tucci, 1993);

b) atribuição de um valor de capacidade máxima de armazenamento de umidade, a cada tipo de solo, a partir de análises em laboratório;

c) determinação da capacidade de infiltração máxima dos solos, com base em formulações que utilizam a capacidade de armazenamento de água como variável. Os ensaios foram realizados com o uso de infiltrômetros de anel;

d) identificação do subsolo, com base no mapa geológico do Estado da Paraíba (Brasil, 1993), para a definição da estimativa da percolação profunda associada a cada estação pluviométrica.

A obtenção do mapa de umidade do solo compreende as seguintes etapas:

- definição do projeto na escala 1:100.000, projeção UTM e unidade de medida em metro;

- criação da base cartográfica do presente estudo (Plano de Informação SOLO) a partir da digitalização do mapa de solos de Silva (1994) no MicroStation. Como ajuste aos objetivos do trabalho, as classes de solo identificadas por Silva op.cit., no PI SOLO, foram agrupadas e sua legenda modificada;

- criação dos demais planos de informação;

- elaboração de um arquivo de regra no formato ASC II, para estabelecer critérios das possíveis combinações dos planos de informação identificados, com a finalidade de obtenção dos valores da umidade do solo de cada mancha associada e dos valores da capacidade de água disponível no solo $(\mathrm{CAD})^{1}$ e da infiltração determinados em campo, resultando na obtenção do mapa de umidade do solo e do déficit hídrico.

\section{RESULTADOS E DISCUSSÃO}

\section{Formação de Banco de Dados}

O banco de dados georreferenciado permitiu a associação dos atributos alfanuméricos aos atributos geográficos de cada um dos grupos de solos estudados (Fig. 1), possibilitando a combinação de um conjunto de informações referentes às características do solo, de cada unidade de mapeamento, aos

\footnotetext{
O valor máximo da quantidade de água que o solo pode reter
}

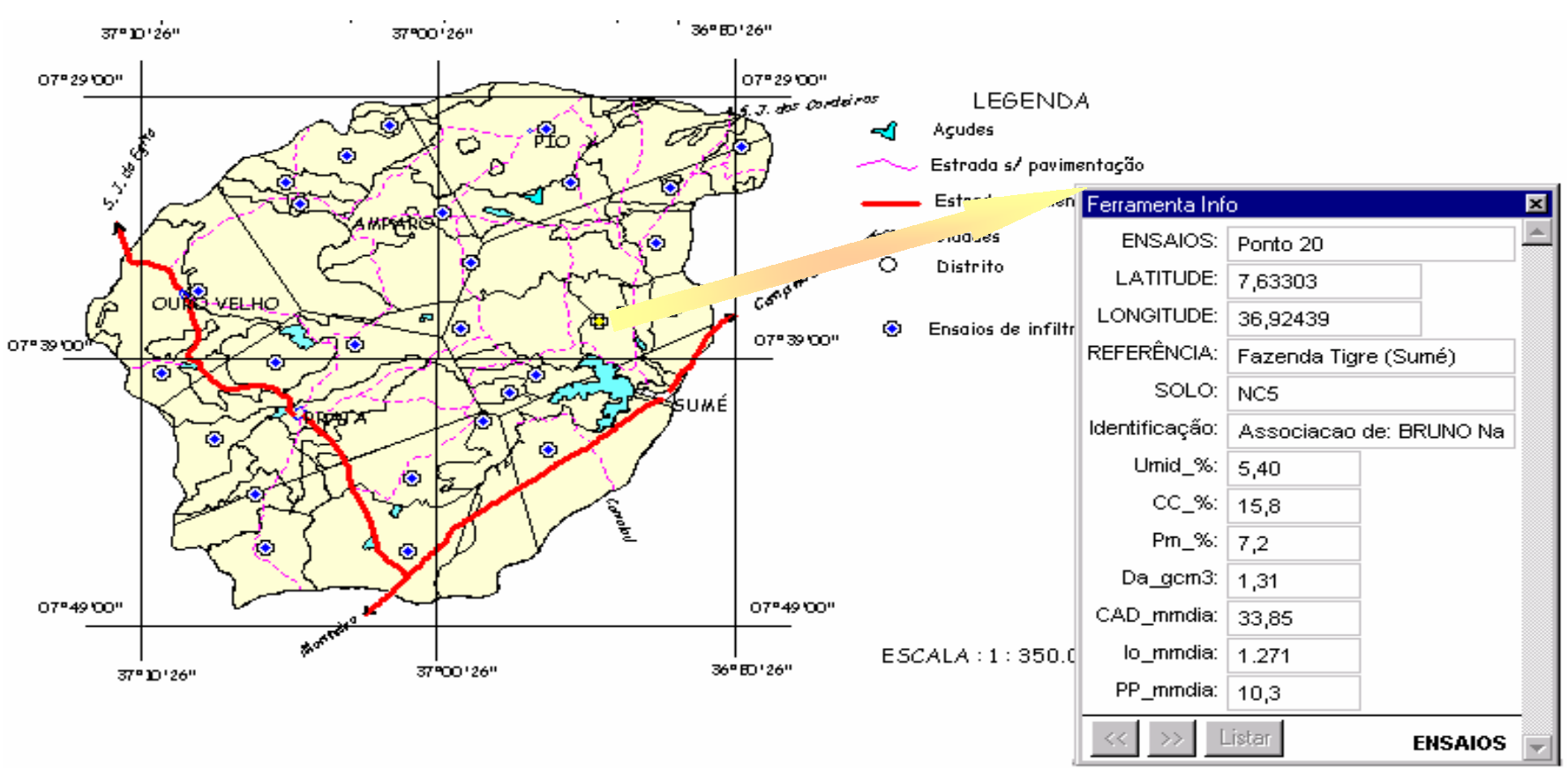

Figura 1. Banco de dados do mapa de solos e dos ensaios de infiltração 
parâmetros capacidade de campo $(\mathrm{CC})$, ponto de murcha permanente (PMP) e densidade aparente (Da) e as informações determinadas no campo e nos ensaios de infiltração.

\section{Análise dos mapas de umidade}

A Figura 2 (A, B e C) mostra um exemplo da distribuição da umidade nos solos para o $1^{\circ}$ decênio do mês de fevereiro, para os anos de 1985, 1999 e 2000, respectivamente. Para o ano de 1985 observa-se a ocorrência de uma boa distribuição da umidade nos solos para toda a área. Já ano de 1999, para o mesmo período, a umidade nos solos não foi constatada.

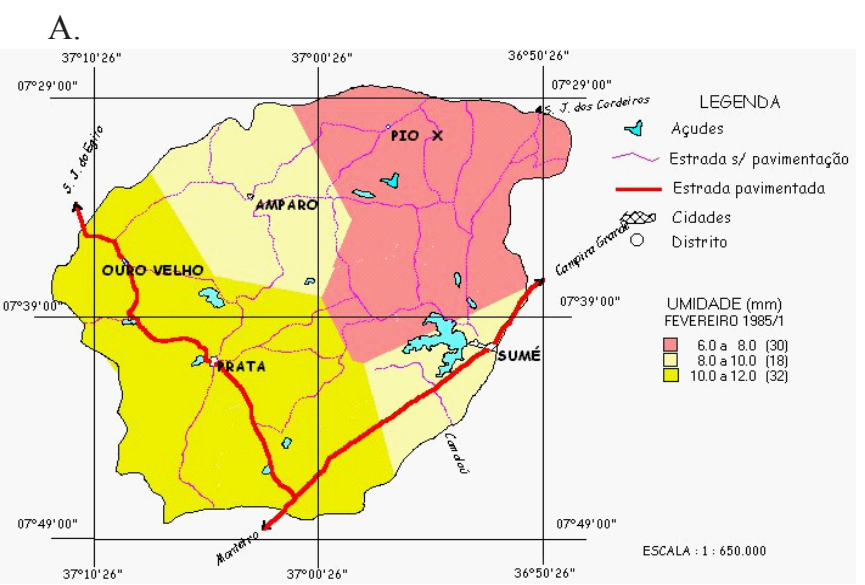

$$
\text { B. }
$$

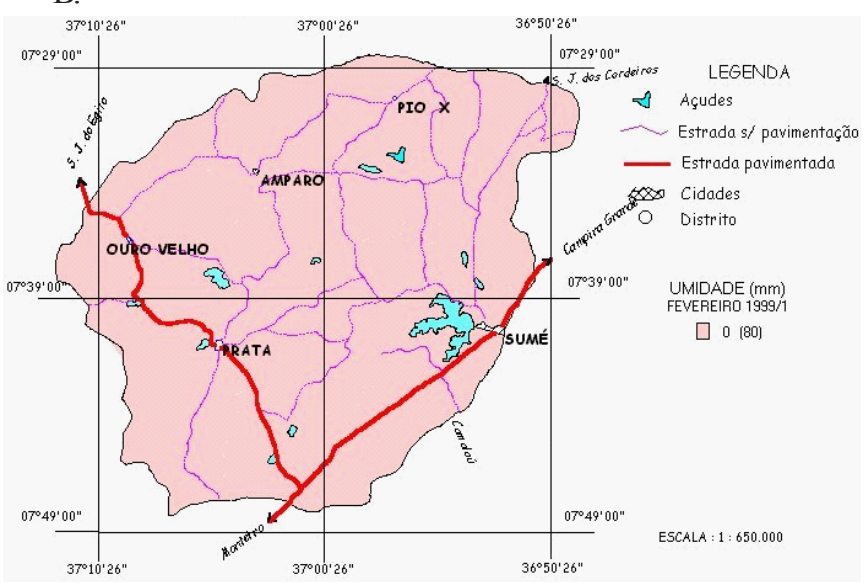

C.

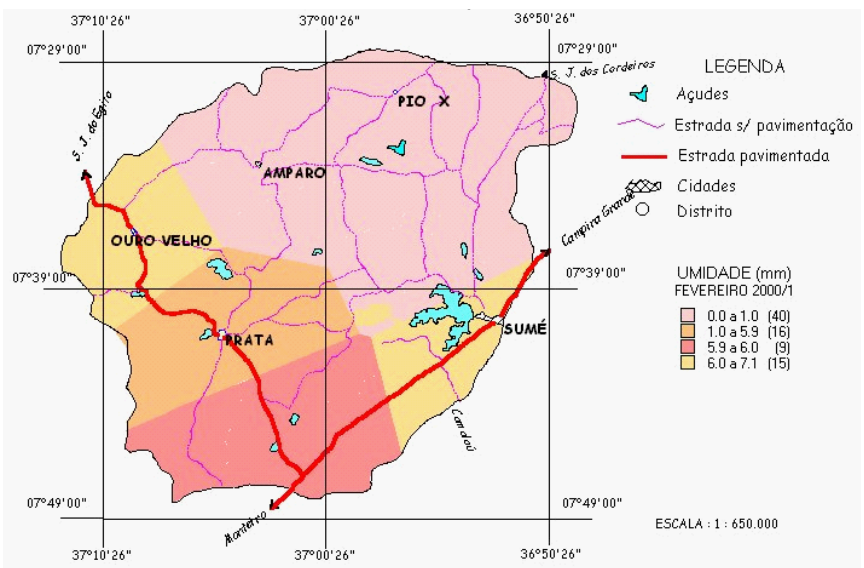

Figura 2. Distribuição da umidade no $1^{\circ}$ decênio de fevereiro para os anos de 1985 (A), 1999 (B) e 2000 (C), nos solos dos municípios de Sumé, Prata, Ouro Velho, Amparo e Monteiro
No ano de 2000, observou-se uma variabilidade na distribuição da umidade nos solos no município de Amparo, em parte do município de Sumé e no distrito de PIO X.

Em testes comparativos, verificou-se que a precisão do sistema é diretamente proporcional à escala do mapeamento dos solos e que, quanto maior for esta precisão, maiores serão as chances da diminuição dos riscos e as vulnerabilidades agrícolas frente às mudanças climáticas causadoras das instabilidades pluviométricas. A técnica desenvolvida nesse estudo tem por finalidade subsidiar, com dados precisos, os tomadores de decisão no planejamento das atividades agrícolas, como a elaboração das políticas de distribuição de sementes aos pequenos produtores, visando o desenvolvimento sustentável com diminuição dos riscos de perdas agrícolas, com aproveitamento ótimo das reservas hídricas (superficiais e de superfície). A metodologia utilizada apresentou vantagens em relação aos métodos tradicionais, possibilitando maior operacionalidade na realização de sobreposição de mapas (cruzamento de dados), no cálculo de áreas, na geração de mapas temáticos (umidade, solos etc.) e maior rapidez e facilidade de atualização da base cartográfica.

Neste sentido, pretende-se estender esta técnica a todo o Estado da Paraíba, para que o pequeno produtor, incentivado e orientado pelas autoridades competentes, faça uso desta ferramenta para definir a melhor época de plantio do milho e do feijão, minimizando ao máximo os riscos de perdas econômicas.

\section{CONCLUSÕES}

1. A tecnologia SIG e o modelo MUSAG utilizados neste trabalho mostraram-se adequados para a geração de banco de dados, de mapas temáticos e para o estudo da distribuição temporal da umidade dos solos.

2. Na geração dos mapas de umidade e de solos, dados essenciais ao processo de avaliação da distribuição da umidade dos solos, o SIG mostrou ser uma ferramenta adequada a tal propósito.

3. O banco de dados georreferenciado proporciona acesso rápido e prático às informações constituindo-se, assim, em uma ferramenta importante na geração de novos conhecimentos.

\section{LITERATURA CITADA}

Brasil. Ministério das Minas e Energia. Mapa Geológico do Estado da Paraíba. 1993.

Doorenbos, J.; Kassam, A.H. Efeito da água no rendimento das culturas. Campina Grande: UFPB, 1994, 306p. Estudos FAO: Irrigação e Drenagem, 33

Molinas, P.A . ; Andrade, F.C.M. de. Um modelo de umidade do solo como ferramenta para avaliação e previsão de atividades agrícolas. In: Simpósio de Recursos Hídricos do Nordeste, 1, 1992, Recife. Anais... Recife: ABRH, 1992.307p.

Silva, F.H.B.B. da. Caracterização dos padrões de drenagem a partir de técnicas de sensoriamento remoto para uso em levantamentos de reconhecimento (alta intensidade) de solos. Campina Grande: UFPB, 1994. 149p. Dissertação Mestrado

Tucci, C.E.N. Hidrologia: ciência e aplicação. Coleção da ABRH1: $1^{\mathrm{a}}$ ed. v.4. Porto Alegre: UFRS, 1993. 943p. 